\title{
The Subjectivity for Closed Adoption of Nursing Students
}

\author{
Sunyoung Jang \\ Dept. of Nursing, Hanseo University,46 Hanseol Ro, Haemi-myun, Seosan-si, \\ Chungcheongnam-do, 369-709, KOREA \\ sjang@hanseo.ac.kr
}

\begin{abstract}
The purpose of this study is to review the subjectivess of nursing students towards closed adoption and describe the characteristics of each type for categorization. Q-methodology was applied for this purpose. Nineteen students enrolled in the third or fourth year of the department ${ }^{1}$ of nursing studies at A university were asked to categorize 42 statements on adoption. The collected data were analyzed using QUANL PC Program. The analysis showed that the perception of nursing students towards closed adoption fell into three categories: coexistence of merits and disadvantages, focus on family, and pessimism about the future. The study was supplied as basic data for identifying the perception of nursing students in clinical settings towards closed adoption and for application of the findings to their education.
\end{abstract}

Keywords: Closed, Adoption, Nursing, Student, Subjectivity, Q methodology

\section{Introduction}

\subsection{Necessity of study}

Closed adoption was carried out often at the request of the birth parents and adoptive parents to protect the birth parents, the child and the adoptive parents from social stigma, but social trend is moving towards a focus on choice, disclosure and the child's rights to know. This has played a major role in leading the adoption culture [1][2][3].

However, despite changes in the times and social awareness, whether to disclose or not the adoption depends on the situation and environment the family finds itself in. Appropriate choices are needed depending on the characteristics or temperament of the parents or the child. The reason adoptive families choose to make it undisclosed is because there is an undesirable prejudice against adoption in Korea. When adoption becomes known, parents have to face the social stigma against infertility, while the child is likely to receive unfair treatment in society. This leads the families to choose closed adoption. Sullivan and Lathrop note that genuine discourse on adoptive families is difficult in a system where closed adoption is the norm, where the rights of the child to know is ignored, where the birth parents are not recognized for their identity and where the adoptive parents need to suppress their sadness over infertility [4].

Closed adoption has become the norm in Korea and still remains so. But due to the lack of interest in closed adoptive families and the emphasis on the families' preference for keeping their lives private led to their adjustment process being little known. Families of closed adoption inform only a limited number of family members of the adoption, often leaving the

Article history:

Received (September 28, 2017), Review Result (November 5, 2017), Accepted (February 13, 2018) 
child himself and other family members in the dark. As such, their perspective towards adoption would be different from that of families of disclosure adoption and therefore it would be meaningful to review the adjustment process the former undergoes.

Nurses not only take up the largest share of personnel in clinical settings, but often have the most frequent contact with beneficiaries of medical services. They are required to provide safe and high quality nursing within a limited time and within a fast changing medical environment [5]. The subjectiveness of the nurse when addressing the patients affect the nursing activity. Therefore, it is important to understand the perception of nurses or students aspiring to become nurses.

Studies on nursing students and their perception towards closed adoption are lacking. Qmethodology allows for an understanding of the characteristics of each category in accordance with the subjective structure of people as it is a methodology that starts from the perspective of the agent rather than the hypothesis of the researcher [6-7]. Since the perception of nursing students towards closed adoption is a uniquely subjective experience, Q-methodology is an appropriate method to verify the types of perception.

As such, this study seeks to understand the subjective structure of closed adoption from the perspective of nurses to provide a set of basic data necessary for developing a differentiated education program for each type of perception towards closed adoption in nursing students before they start working in a clinical setting.

\subsection{Purpose of study}

The purpose of the study is to apply Q-methodology to identify the subjective perception of nursing students towards closed adoption and the characteristics of each type to provide information on nursing students that are starting work on closed adoption to provide a set of basic data that can be applied to teaching nursing students. Specific study goals are as follows.

1) The subjective perceptions of nursing students towards closed adoption are categorized.

2) The characteristics of each type of perception towards closed adoption are analyzed and described.

\section{Method of study}

\subsection{Design of study}

The purpose of this study was to identify the type of subjective perception of open adoption in nursing students who experienced open adoption after reviewing literature, media data and previous studies on open adoption.

\section{2. $Q$ population and $Q$ sample selection}

To extract a comprehensive statement on the effect on open adoption, the Q population was derived from a review of domestic and foreign literature, an open questionnaire, and individual in-depth interviews focusing on current nursing students. Through this process, over 200 Q-populations from three domains were extracted, and in addition to that, by integrating the literature collected through the review of domestic and foreign literature, a total of $100 \mathrm{Q}$ populations were extracted. After reviewing and revising the extracted $\mathrm{Q}$ samples, the final 42 samples with high discriminative power were selected. 


\subsection{Design of Study}

The Q-methodology is not a personal difference but a qualitative research that emphasizes individual inertia by emphasizing differences in meaning or importance within an individual, and it is based on the small sample doctrine that when a P sample grows, several people are biased on one factor and their characteristics are not clearly revealed[8]. The $\mathrm{P}$ sample consists of a total of 19 students who are expected to participate in the study after fully explaining the purpose of the study to the students enrolled in the nursing department.

\subsection{Classification and data analysis method}

The $\mathrm{Q}$ classification process is a process by which individuals who are selected as a $\mathrm{P}$ sample classify the statement of the Q sample as a forced normal distribution method, thereby creating a spontaneous definition of the companion animal by each individual. We collected data by using the $\mathrm{Q}$ card for 25 students of OO College of Nursing. The time required for one subject to complete the Q classification was 30-45 minutes. The distribution of the $\mathrm{Q}$ sample was classified from the strong positive to the strong negative in order of the importance of the subjects' opinion. The statements on open adoption (Q1) were classified on a 12-point scale. Afterwards, the subjects were interviewed about the statements classified at the extremes. The Q factor analysis used the Principal Component Factor Analysis, varimax. The type classification was selected based on the Eigen value of 1.0 or more and the number of factors and the total explanatory variable. The collected data were scored from 1 to 15 , with the conversion scores assigned to each, focused on the card distributed by the $\mathrm{Q}$ sample distribution table. The assigned conversion scores were coded in the $\mathrm{Q}$ sample order and processed by the main factor analysis by the QUANL PC program. Analysis of the data was done by the QUANL PC program.

\subsection{Ethical Considerations for the Subject}

After a volunteer consent was obtained from the subjects before the study, we explained to the subject that they could stop at any time during the study. To respect the rights of the subjects and ensure the confidentiality of the subject's privacy and information, all of the information collected through this study is treated as anonymous in the whole process of the data analysis and coded with Q sorting.

\section{Result of study}

Using the QUANL pc program, a Q factor analysis of the subjectiveness of nursing students towards closed adoption showed there to be three type categories.

- 'Co-existence of merits and disadvantages' type: They thought that regardless of whether the adoption is disclosed or not, forming an attachment relationship depends on the love and interest of the parents and that raising awareness through social and governmental programs can be helpful. They did not see adoption as something to be embarrassed about or hide and considered both the merits and the disadvantages of closed adoption. As such, the first type was named 'co-existence of merits and disadvantages'.

- 'Focus on family' type: They would be best advised to prepare in advance of situations where the adoption becomes known by the child or by friends and family. If the child is taught that adoption is not a negative thing, he can accept it without resistance at a later point when he learns of it. The subjects in this type focused on the reason for selecting closed 
adoption and sees it as a willingness to maintain the family line. As such, type 2 was named 'focus on family'.

- 'Pessimism about the future' type: This means that it is important to provide information about his adoption to the child through an open adoption while treating him like a blood family when bringing him up. Even if most adoptions are closed and lead to many disadvantages, it would not toward adoption from becoming mainstream. Behaviors to mimick pregnancy would also be unnecessary. As such, this third type was named 'pessimism about the future'.

Table 1. Q-statements on new nurse images type of representative items and Z-scores. $(\mathrm{N}=19)$

\begin{tabular}{|c|c|c|c|c|}
\hline Factor & No & Description & Mean (SD) & Z-score \\
\hline \multirow{3}{*}{$\begin{array}{l}\text { Factor } 1 \\
(\mathrm{~N}=8)\end{array}$} & 37 & Contact with the birth mother is avoided. & 7.88(2.357) & 1.99 \\
\hline & 11 & $\begin{array}{l}\text { The character of the child after learning of his } \\
\text { adoption changes negatively. }\end{array}$ & $6.25(2.866)$ & 1.76 \\
\hline & 17 & $\begin{array}{l}\text { There is fear of the child being admitted to the } \\
\text { hospital when a child of different blood type is } \\
\text { adopted. }\end{array}$ & $6.38(1.996)$ & 1.72 \\
\hline \multirow{3}{*}{$\begin{array}{l}\text { Factor } 2 \\
(\mathrm{~N}=5)\end{array}$} & 29 & $\begin{array}{l}\text { The parents suffer from undermined mental and } \\
\text { physical energy. }\end{array}$ & $7.80(1.924)$ & 2.49 \\
\hline & 7 & The child can be brought up as if he is one's own. & $7.20(2.387)$ & 1.72 \\
\hline & 17 & $\begin{array}{l}\text { There is fear of the child being admitted to the } \\
\text { hospital when a child of different blood type is } \\
\text { adopted. }\end{array}$ & $6.20(3.194)$ & 1.50 \\
\hline \multirow{3}{*}{$\begin{array}{l}\text { Factor } 3 \\
(\mathrm{~N}=6)\end{array}$} & 9 & $\begin{array}{l}\text { The parents feel the burdened to hide the adoption } \\
\text { throughout their life. }\end{array}$ & $7.83(2.041)$ & 2.35 \\
\hline & 17 & $\begin{array}{l}\text { There is fear of the child being admitted to the } \\
\text { hospital when a child of different blood type is } \\
\text { adopted. }\end{array}$ & $5.33(2.251)$ & 1.99 \\
\hline & 1 & $\begin{array}{l}\text { There is fear of that the child would learn of his } \\
\text { adoption. }\end{array}$ & $8.50(2.429)$ & 1.63 \\
\hline
\end{tabular}

\section{Discussion}

This study categorized the subjective perceptions of nursing students towards closed adoption into three types. The study found that most nursing students were concerned about the confusion or pain that could be experienced by the adoptee in a closed adoption. Despite such concerns, they believed that it is desirable to promote adoption in Korea and to help families of adoption through various programs. The three types were categorized based on their characteristics as follows: co-existence of merits and disadvantages, focus on family and pessimism about the future.

This study on subjectiveness can be used as basic data in developing an alternative to promote open adoption which is increasingly garnering interest in recent years. Moreover, by presenting the subjective structure and characteristics of each type of perception in nursing students, the data can be used for developing a differentiated education program for future nurses. 
But the study is limited in that it only used one university as a subject and did not select the participants by taking into account all factors that affect the perception towards closed adoption. As such, the findings of this study cannot be generated. Additional verification on the type categories would be needed in a follow-up by composing a Q sample with subjects of more varied backgrounds.

\section{Conclusion}

This study was carried out by applying Q-methodology to provide basic data needed to explore measures for promoting closed adoption, based on the data analzying the subjective perceptions of nursing students towards closed adoption. The study found three factors in their perceptions - co-existence of merits and disadvantages, focus on family and pessimism about the future.

This study, in categorizing the subjectiveness of nursing students towards closed adoption, provides basic data needed to adopt or apply policies to promtoe close adoption. This researcher hopes that the findings of the study can lead to a development of education programs that take into account the characteristics of each category type. Moreover, a qualitative study to verify the various factors that affect the nursing of children of closed adoption, as well as a follow-up study on the type categorization by using samples with various factors, is suggested.

\section{References}

[1] J.M. Kwon, "The dilemma of so-called baby box: Safe haven for abandoned babies` lives or unintended substitute for legal adoption," Study of Low, vol.22, no.1, pp.59-85, (2014)

[2] K. Kim, "Determinants of family functioning of adoptive parents who chose open adoption in Korea," Study of Local Self-government, vol.13, pp.133-158, (2009)

[3] W. S. Kim, "A phenomenological study on the adoption experience of infertile women," Journal of Family and Counselling, vol.2, no.2, pp.49-73, (2012)

[4] D. Sullivan and E. Lathrop, "Openness in adoption: Retrospective lessons and prospective choices," Children and Youth Services Review, vol.26, pp.393-411, (2004)

[5] S. Dyess and C. Parker, "Transition support for the newly licensed nurse: A programme that made a difference," Journal of Nursing Management, vol.20, pp.615-623, (2012)

[6] W. Stephenson, "Q-methodology, interbehavioral psychology and quantum theory," Psychol Record, vol.32, pp.235-248, (1982)

[7] H.K. Kim, "Q methodology: Philosophy, theories, analysis, and application," Seoul: CommunicationBooks, (2008)

[8] S.M. Whang, S.W. You, J.Y. Kim, and R.G. Kim, "Consumer types and cultural consumption characteristics of Korean Society: Who spends for what reasons?” Journal of Human Subjectivity, vol.13, pp.25-39, (2006) 
The Subjectivity for Closed Adoption of Nursing Students

This page is empty by intention. 